\title{
BMJ Open Consensus study to define appropriate inaction and inappropriate inertia in the management of patients with hypertension in primary care
}

\author{
Jean-Pierre Lebeau, ${ }^{1}$ Julie Biogeau, ${ }^{1}$ Maxime Carré, ${ }^{1}$ Alain Mercier, ${ }^{2}$ \\ Isabelle Aubin-Auger, ${ }^{3}$ Emmanuel Rusch, ${ }^{4}$ Roy Remmen, ${ }^{5}$ Etienne Vermeire, ${ }^{5}$ \\ Kristin Hendrickx ${ }^{5}$
}

To cite: Lebeau J-P, Biogeau J, Carré $\mathrm{M}$, et al. Consensus study to define appropriate inaction and inappropriate inertia in the management of patients with hypertension in primary care. BMJ Open 2018;8:e020599. doi:10.1136/ bmjopen-2017-020599

- Prepublication history and additional material for this paper are available online. To view these files, please visit the journal online (http://dx.doi. org/10.1136/bmjopen-2017020599).

Received 16 November 2017

Revised 8 March 2018

Accepted 23 May 2018

Check for updates

(C) Author(s) (or their employer(s)) 2018. Re-use permitted under CC BY-NC. No commercial re-use. See rights and permissions. Published by BMJ.

${ }^{1}$ Department of General Practice, EES Research Team, University of Tours, Faculté de Médecine, Tours, France

2Department of General Practice University Paris 13, UFR SMBH, Tours, France

${ }^{3}$ Department of General Practice REMES Research Team,

University Paris Diderot, Paris,

France

${ }^{4}$ Department of Public Health,

EES Research Team, University

of Tours, Paris, France

${ }^{5}$ Department of Primary and Interdisciplinary Care, University of Antwerp, Wilrijk, Belgium

Correspondence to

Professor Jean-Pierre Lebeau;

lebeaujeanpierre@yahoo.fr

\section{ABSTRACT}

Objectives To elaborate and validate operational definitions for appropriate inaction and for inappropriate inertia in the management of patients with hypertension in primary care.

Design A two-step approach was used to reach a definition consensus. First, nominal groups provided practice-based information on the two concepts. Second, a Delphi procedure was used to modify and validate the two definitions created from the nominal groups results. Participants 14 French practicing general practitioners participated in each of the two nominal groups, held in two different areas in France. For the Delphi procedure, 30 academics, international experts in the field, were contacted; 20 agreed to participate and 19 completed the procedure.

Results Inappropriate inertia was defined as: to not initiate or intensify an antihypertensive treatment for a patient who is not at the blood pressure goals defined for this patient in the guidelines when all following conditions are fulfilled: (1) elevated blood pressure has been confirmed by self-measurement or ambulatory blood pressure monitoring, (2) there is no legitimate doubt on the reliability of the measurements, (3) there is no observance issue regarding pharmacological treatment, (4) there is no specific iatrogenic risk (which alters the riskbenefit balance of treatment for this patient), in particular orthostatic hypotension in the elderly, (5) there is no other medical priority more important and more urgent, and (6) access to treatment is not difficult. Appropriate inaction was defined as the exact mirror, that is, when at least one of the above conditions is not met.

Conclusion Definitions of appropriate inaction and inappropriate inertia in the management of patients with hypertension have been established from empirical practice-based data and validated by an international panel of academics as useful for practice and research.

\section{INTRODUCTION}

Uncontrolled hypertension remains a major public health issue. As public health objectives in this field are often not reached, complications of hypertension account for
Strengths and limitations of this study

- Initial data gathered 'from the ground up', by nominal groups of practicing general practitioner (GPs), provided practice based elements for the definitions.

- As a limitation, grouping GPs responses into categories and creating the definitions was done by the research team.

- Two teams worked independently on this step of the process and came up with equivalent results. These results were validated by the nominal groups participants.

- The Delphi procedure included a panel of 19 renowned experts worldwide. All of them completed the procedure.

- The experts also validated the usefulness of the definitions, for practice and for research.

9.4 million deaths worldwide every year, indicating significant room for improvement. ${ }^{12}$

This situation reflects the existing gap between guidelines for treatment based on high-level evidence and the realities of daily practice. One reason may be ineffective dissemination of the guidelines, but after optimising, there was little improvement of their application in hypertension. ${ }^{3} 4$ Other reasons are patient-related issues, such as lack of adherence to treatment and suboptimal lifestyle. ${ }^{56}$ Others are inherent to the health system and, more widely, relate to politics and economics: difficulties and inequalities in access to healthcare, insurance and reimbursement issues. ${ }^{7}$ Finally, the healthcare provider may not initiate or modify a drug treatment as recommended in the guidelines. This factor relates to the healthcare provider, and has been defined as clinical or therapeutic inertia. ${ }^{8}$

Clinical inertia was first defined in 2001 by Lawrence Philips as: 'health care providers often 
do not initiate or intensify therapy appropriately during visits of patients with these problems. We define such behavior as clinical inertia-recognition of the problem, but failure to act ${ }^{8}$. In 2006, Okonofua et al used the terms 'therapeutic inertia' (TI) with the exact same definition. ${ }^{9}$ Since then, either terms have been used indifferently.

TI plays a major role in the failure to reach individual and public objectives of hypertension control. Up to $85 \%$ of primary care visits regarding hypertension end with therapeutic inertia, and thus may result in a large portion unachieved targets. ${ }^{10}$ Calls to action and numerous trials have tried to motivate and find ways to overcome TI. ${ }^{11} 12$ At the same time, some authors have pointed out clinical realities can be complex, and that inaction from the health provider can be the right attitude for certain patients. ${ }^{13}$ It appears that the causes and mechanisms of TI, as well as the clinical and care situations in which it occurs warrant exploration. Such an examination requires a clear concept and an operational definition to rely on. Our recent literature review found very little agreement between authors on this definition, and we concluded that TI remains a blurry concept. We suggested that the TI concept should be split in two concepts: appropriate inaction and inappropriate inertia. ${ }^{14}$ Further, we proposed that operational definitions based on empirical data were needed for primary care research and practice.

The objective of this work was therefore to create and validate operational definitions for appropriate inaction and for inappropriate inertia in the management of patients with hypertension in primary care.

\section{METHOD}

\section{Methodology background}

These definitions should reflect clinical reality and be operational in primary care. Empirical data were therefore needed to construct these definitions from the ground up, requiring a high level of input from practitioners. This ensured that every possible issue encountered in this situation would be taken into account in the definitions. Next, definitions had to be consensual and operational for research, which meant they had to be validated by academic experts.

A two-step approach was used to in order to meet these specifications and reach a consensus (figure 1$)^{15}{ }^{16}$ : First, nominal groups were held with practicing general practitioners (GPs). They provided practice-based information on the two concepts. ${ }^{16}{ }^{17}$ Second, a panel of international academic experts in the field used a modified Delphi procedure to refine and validate the two definitions created using the results of the nominal groups. ${ }^{1516}$

\section{Nominal groups}

\section{Recruitment of participants}

All participants were practicing GPs in France. They were recruited by phone, email and snowballing in two areas (surrounding Paris and Orléans). Sampling was purposive with a maximum variation in terms of age, gender, years
Step 1. Nominal groups

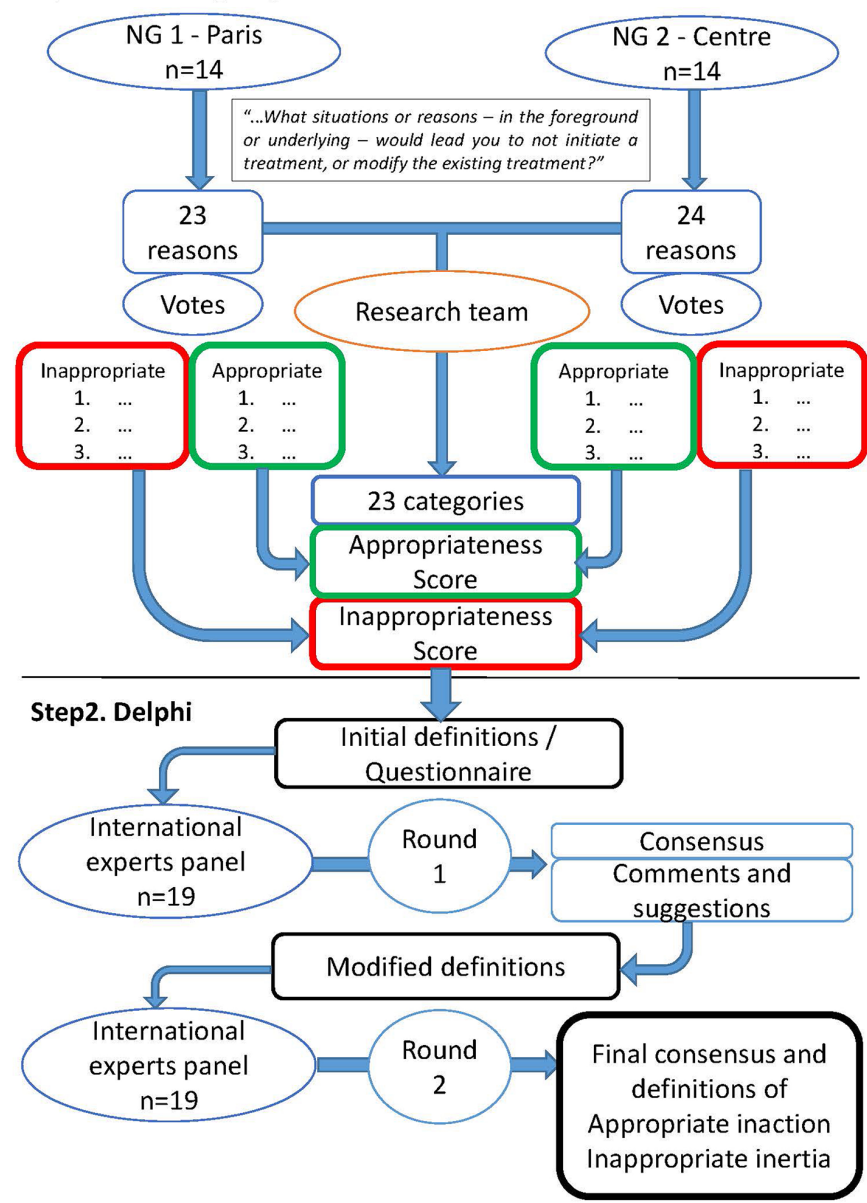

Figure 1 Flow chart. NG, nominal group.

of practice, type of practice (group, single, primary care clinic and locum), location (urban/rural) and academic involvement. GPs who agreed to participate received an informed consent form and a compensation $(100 €$ per participant).

\section{Nominal groups timeline}

Participants were first asked to list individually on paper all possible answers to the question:

You meet, at your practice or at home, a patient whose blood pressure is above the threshold defining hypertension for this patient. What situations or reasons - in the foreground or underlying - would lead you to not initiate a treatment or modify the existing treatment?

The group then further discussed each answer, rephrased unclear formulations and grouped similar answers under a new consensual formulation. Participants were then asked to vote on two separate secret ballots. The first one listed the three answers regarded by the participant as the most appropriate ones for 'not initiating a treatment, or modifying the existing treatment'. These answers had to be ranked by the participant as first, second and third most important, and were 
weighted three, two and one point, respectively. The second ballot listed and ranked the most inappropriate reasons.

\section{Nominal group analysis}

The research team conducted a thematic qualitative analysis of the group results. Situations and reasons evoked by the participants were grouped into categories. Categorisation was done independently by two teams consisting of two researchers each (JPL-MC/JB-ER). Discrepancies were resolved by discussion and if needed arbitration by a third team (AM-IAA).

Two scores were then attributed to each category. The Appropriateness Score was the sum of weighted votes attributed to each item of the category for being the most appropriate reasons or situations for 'not initiating a treatment or modifying the existing treatment'. The Inappropriateness Score was the sum of weighted votes attributed to each items of the category for being the most inappropriate reasons or situations.

Two proposed definitions for appropriate inaction and for inappropriate inertia in the management of patients with hypertension in primary care were created by the research team from the final results of the nominal groups.

The final results and definitions were sent to the participants 3 months after the meetings, together with a feedback questionnaire including two questions: (1) do these results match with your recollection of the meeting? (2) do these results match with your practice? Participants were asked to answer these two questions on Likert scales ranking from 0 to 4 and to make any comments that they wished.

\section{Modified Delphi procedure}

\section{Recruitment of participants}

The participants were recruited by email among international experts in the field of TI and/or hypertension. They were academics with published articles in this field that were identified during the literature review. ${ }^{14}$ Those who agreed to participate received an informed consent form, a detailed summary of former research including the results of the nominal groups and the first Delphi questionnaire (box 1). A minimum number of 15 participants remaining at the end of the process was expected. ${ }^{18}$

\section{Delphi procedure timeline}

The entire procedure was conducted anonymously by email, without any contact between the participants.

The first round was based on the two definitions resulting from the nominal groups. Participants were asked to score and comment their level of agreement with the proposals from the nominal groups. The level of agreement with each proposal was scored using Likert scales ranking from 1 (totally disagree) to 9 (totally agree). Participants were invited to systematically comment on their answers. A comment was mandatory for any score under 4.
Box 1 Questionnaire for the first round of the Delphi procedure

1. Taking into account the results of the literature review summarised above, do you consider that the current (Phillips') definition of therapeutic (or clinical) inertia in hypertension is:

- Comprehensive (taking in account all the components that are likely to take part in the phenomenon)?

2. Taking into account the results of the literature review summarised above, do you consider that the current (Phillips') definition of therapeutic (or clinical) inertia in hypertension is:

- Operational (providing a reliable and working basis) for clinical research (relevant assessment criteria)?

- Operational for practice (useful for the therapeutic decision)?

- Operational in any case?

3. From the data collected in the systematic review and in the nominal groups, appropriate inaction in hypertension can be defined as: (definition)

- Do you agree with this global proposition?

- What is your proposition, which modification(s) would you bring to this definition?

4. From the data collected in the systematic review and in the nominal groups, inappropriate inertia in hypertension can be defined as: (definition)

- Do you agree with this global proposition?

- What is your proposition, which modification(s) would you bring to this definition?

5. The splitting of therapeutic inertia in hypertension into two different entities as mentioned above is:

- Useful for clinical research?

- Useful for practice?

- Useful in any case?

In analysing the results, a proposal was either accepted (median from 7 to 9 inclusive) or rejected (median from 1 to 3 inclusive) or could remained in doubt (median from 4 to 6 inclusive). Disagreement between the experts meant that at least $30 \%$ of the experts scored their agreement from 1 to 3 , and at least $30 \%$ of the experts scored their agreement from 7 to 9 .

Consensus on accepting a proposal was reached when the proposal was accepted with no disagreement between experts. Consensus on rejecting a proposal was reached when the proposal was rejected with no disagreement between experts. Any other situation (proposal remaining in doubt and/or disagreement between experts) regarding a proposal would lead to a second round, with possible changes in the proposal according to participants' comments.

For the following rounds, each participant received the initial questionnaire with a reminder of his/her answers, a histogram of the answers from all respondents to each question, all comments of all expert participants (translated if needed) and the questionnaire for the second round. Experts were asked to rethink their answers after reading the other participants' comments and answer to the proposals in the second questionnaire.

To prevent exhaustion of participant motivation, a maximum of three rounds was planned. ${ }^{16}$ 
Table 1 Characteristics of the GPs involved in the nominal groups

\begin{tabular}{|c|c|c|}
\hline & $\begin{array}{l}\text { Group } 1 \\
\text { (Paris area) }\end{array}$ & $\begin{array}{l}\text { Group } 2 \\
\text { (Orléans } \\
\text { area) }\end{array}$ \\
\hline Number of participants & 14 & 14 \\
\hline Men & 7 & 11 \\
\hline Women & 7 & 3 \\
\hline Age, years & $29-53$ & $28-64$ \\
\hline Median & 33.5 & 45 \\
\hline \multicolumn{3}{|l|}{ Mean (SD) } \\
\hline Overall & $37(7.9)$ & $45(12,6)$ \\
\hline Men & $37(7.1)$ & $49(11.0)$ \\
\hline Women & $37(8.6)$ & $30(2.3)$ \\
\hline \multicolumn{3}{|l|}{ Years of practice } \\
\hline Mean (SD) & $8.9(8.6)$ & $15,7(11.1)$ \\
\hline Median & 5 & 16.5 \\
\hline \multicolumn{3}{|l|}{ Practice characteristics } \\
\hline Group practice & $6(42.8 \%)$ & $9(64.3 \%)$ \\
\hline Single practice & 0 & $1(7.2 \%)$ \\
\hline Private primary care clinic & 0 & $4(28.6 \%)$ \\
\hline Public primary care clinic & $3(21.4 \%)$ & 0 \\
\hline Locum & $5(35.7 \%)$ & 0 \\
\hline Urban & $14(100 \%)$ & $8(57.1 \%)$ \\
\hline Urban/rural & 0 & $2(14.2 \%)$ \\
\hline Rural & 0 & $4(28.7 \%)$ \\
\hline $\begin{array}{l}\text { Special interest } \\
\text { (gynaecology, sport medicine, nutrition } \\
\text { and so on) }\end{array}$ & $3(21.4 \%)$ & $2(14.3 \%)$ \\
\hline \multicolumn{3}{|l|}{ Professional commitment and CME } \\
\hline CME & $12(85.7 \%)$ & $12(85.7 \%)$ \\
\hline Medical journals & $14(100 \%)$ & $14(100 \%)$ \\
\hline Academic involvement & 7 (50\%) & $6(42.8 \%)$ \\
\hline Sees medical sales representatives & $6(42.9 \%)$ & $5(35.7 \%)$ \\
\hline $\begin{array}{l}\text { Participants suffering from a chronic } \\
\text { disease }\end{array}$ & $1(7.2 \%)$ & 0 \\
\hline \multicolumn{3}{|l|}{ Usual blood pressure measurement device } \\
\hline Manual & $7(50 \%)$ & $6(42.8 \%)$ \\
\hline Electronic & $4(28.6 \%)$ & $7(50 \%)$ \\
\hline Any & $3(21.4 \%)$ & $1(7.2 \%)$ \\
\hline $\begin{array}{l}\text { Use of ambulatory blood pressure } \\
\text { measurement }\end{array}$ & $13(92.9 \%)$ & $14(100 \%)$ \\
\hline $\begin{array}{l}\text { Possible loan of a device to the } \\
\text { patient }\end{array}$ & $6(42.9 \%)$ & $12(85.7 \%)$ \\
\hline
\end{tabular}

BP, blood pressure; CME, continuing medical education.

\section{Patient and public involvement}

No patient nor public was involved in this study.

\section{RESULTS}

\section{Nominal groups}

Fourteen participants attended each of the two meetings. Characteristics of the participants are detailed in table 1.
The first group (NG1) produced a list of 23 reasons or situations to not initiate or increase the treatment (table 2, column 1). The second group (NG2) produced a list of 24 (table 2 , column 2). These answers were secondarily interpreted and grouped into 23 categories by the researchers (table 2, column 3). Nine answers could not be grouped with others and remained as separate categories. The appropriateness and inappropriateness scores for each category were calculated (table 2). The research team constructed definitions of AI and inappropriate TI from these results (box 2).

Twenty-three participants (12NG1 and 11NG2) answered the feedback questionnaire. They all answered: 'totally agree' or 'fairly agree' to both questions. No further remarks or comments were made.

\section{Modified Delphi procedure}

An initial list of 30 experts was established. Seven did not reply to the letter of invitation, 3 refused to participate and 20 agreed. One participant withdrew without answering the first questionnaire. The remaining 19 experts involved completed all the questionnaires and finished the study (online supplementary file 1).

\section{First round}

Table 3 details the experts' answers to each question. Although a consensus was already reached for some questions after the first round, and because the comments were so rich, it was decided that the entire questionnaire would be sent for a second round. Comments and suggestions led to the modification of the initial definitions:

Item 2: 'doubt' was changed to 'legitimate doubt'. Experts meant to make sure that the doubt relied on evidence of malfunction of the device used or inappropriate method and not only on the practitioner's subjectivity.

Item 3: ('the difference between the measurement and recommended target is (not) significant') was removed. Some experts argued that if you consider that a difference of a few $\mathrm{mm} \mathrm{Hg}$ with the threshold may not be significant, then you are simply redefining the threshold.

Item 4: 'there is an (no) observance issue (including lifestyle and diet)' was changed to 'regarding pharmacological treatment'. Some experts commented that there will always be observance issues regarding lifestyle and diet, and therefore always a door open to inaction.

The term 'observance issue', instead of the more usual 'non-adherence' was used because the participants of the NGs insisted that 'non-adherence' did not adequately describe what they meant, as it seemed to imply a wilful or intentional decision and was limited to medication. No expert of the Delphi panel commented on that term.

Item 5: some experts insisted that 'orthostatic hypotension in the elderly' should be enhanced as the most usual iatrogenic risk in daily practice.

Item 6: many experts insisted that 'the door should be closed' to 'minor so-called priorities as excuses for 


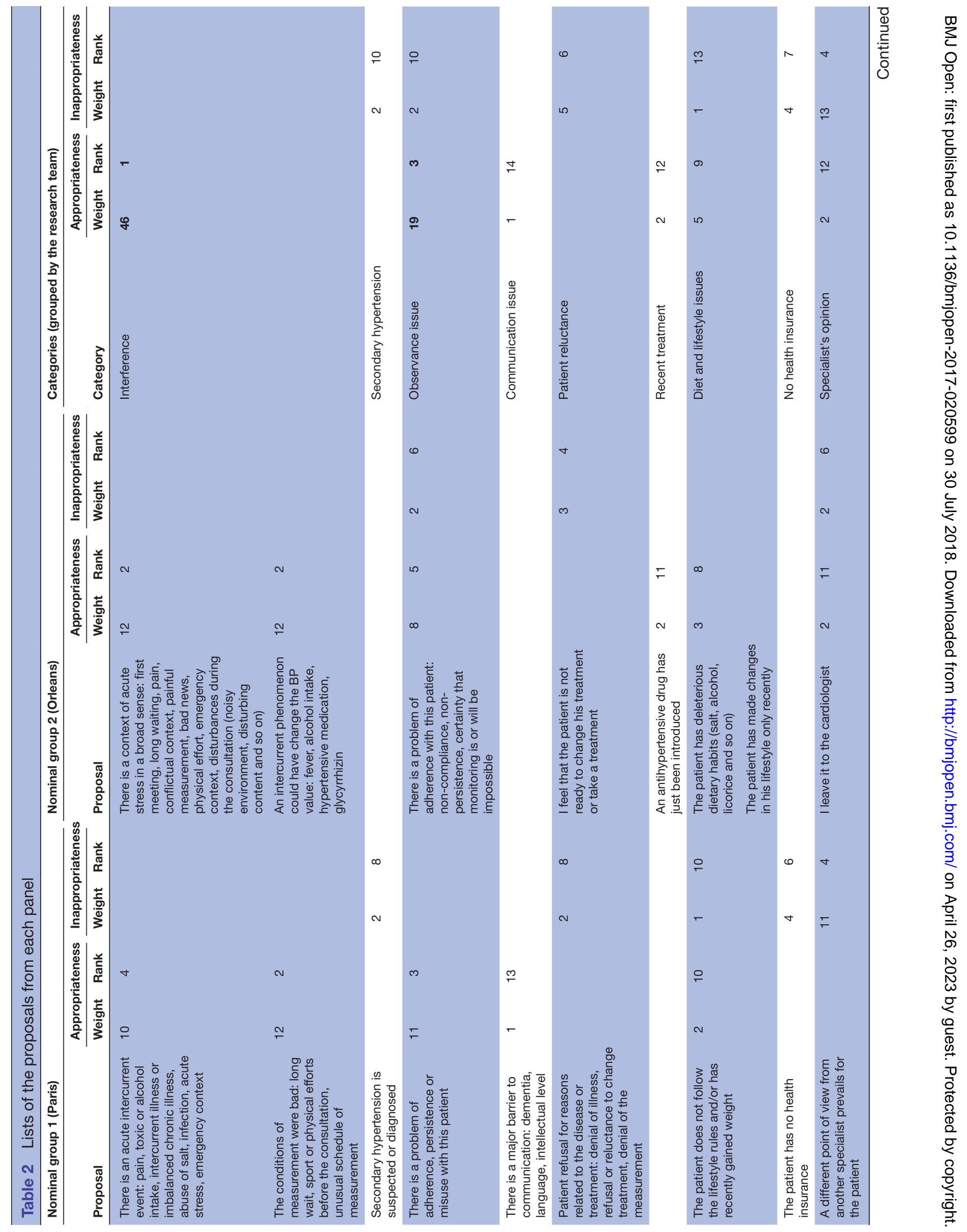




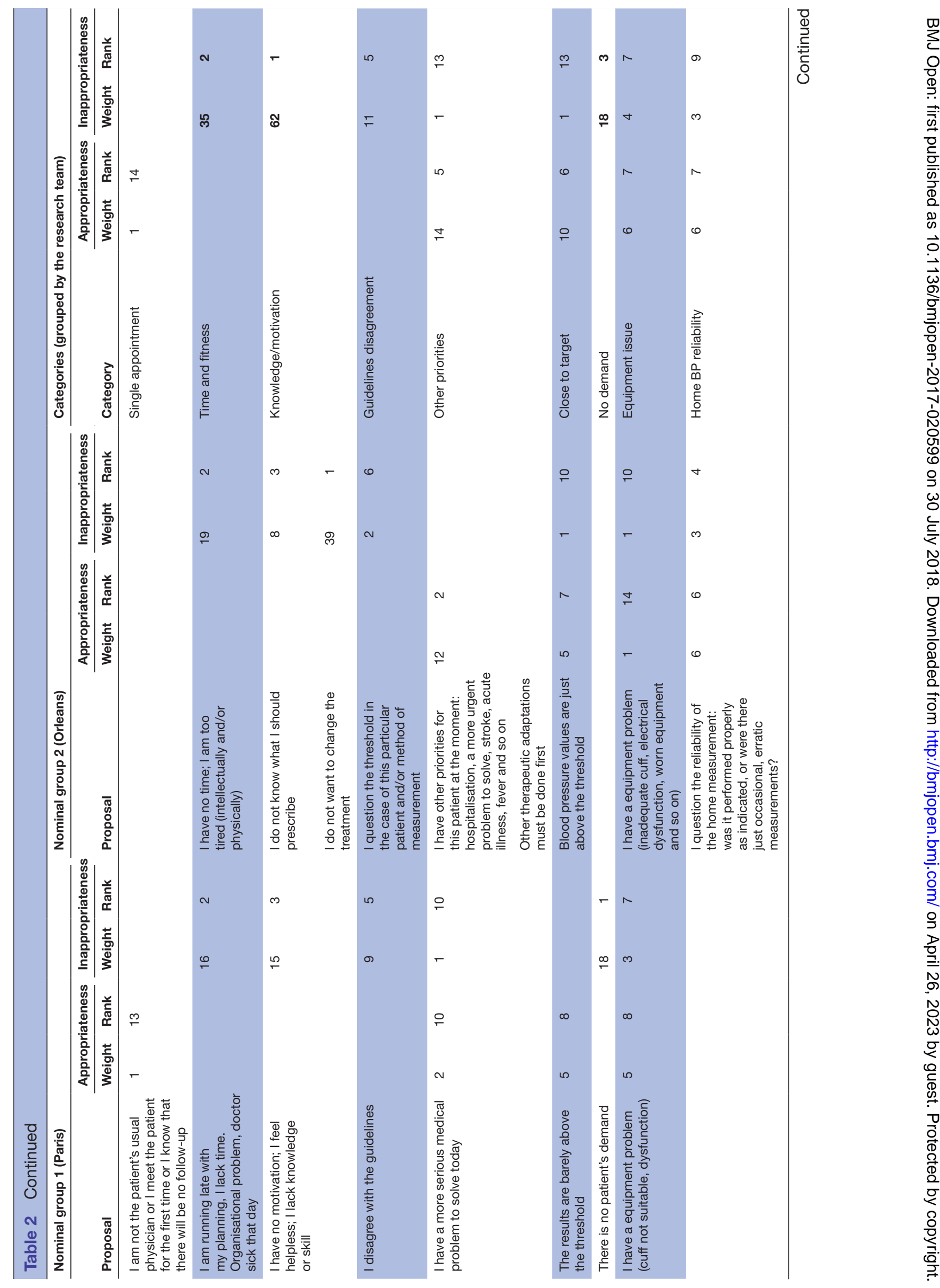

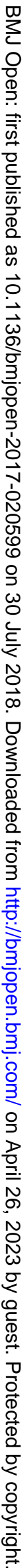




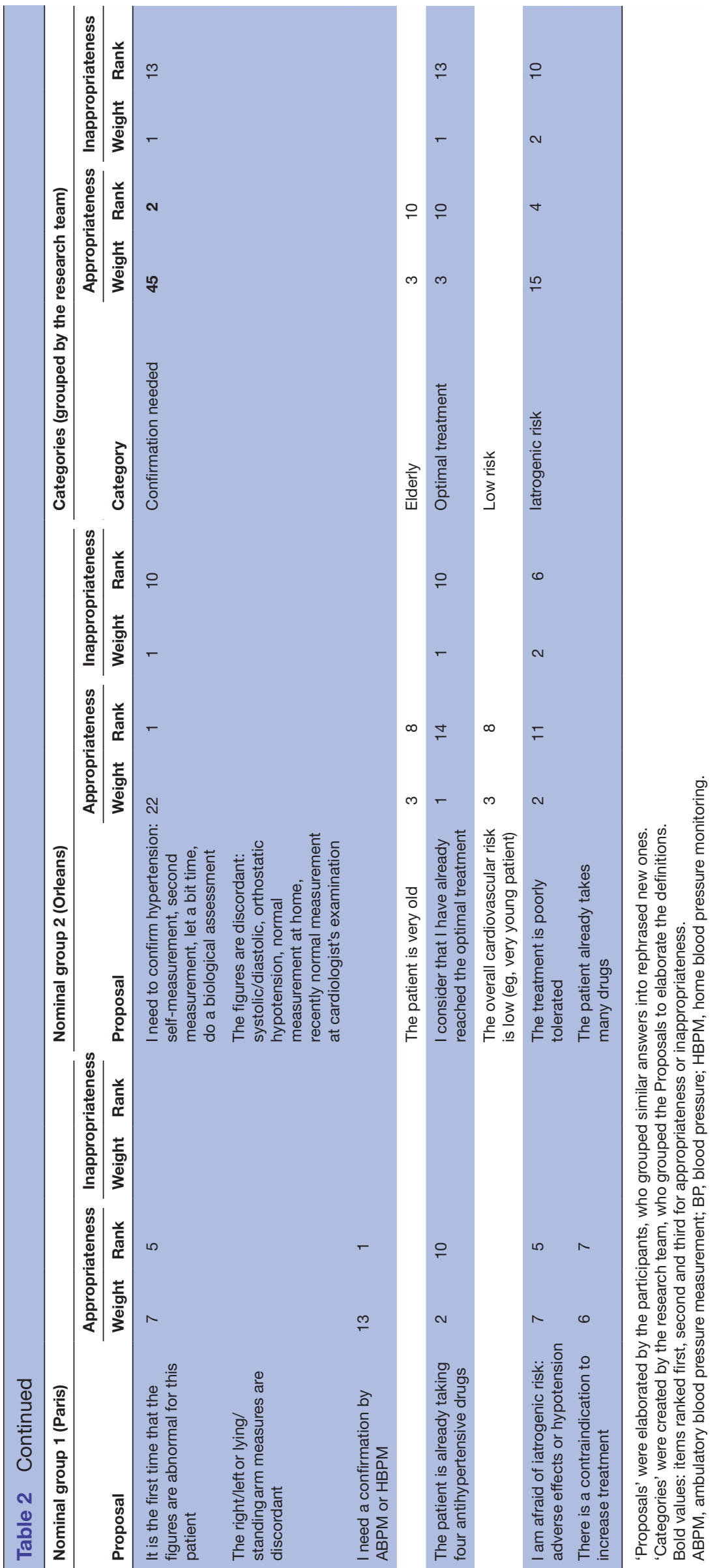

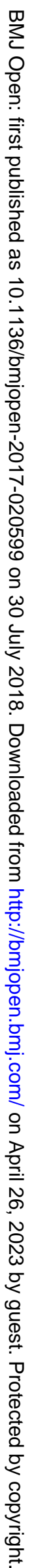


Box 2 Definitions created from the results of the nominal groups

Inappropriate therapeutic inertia means not initiating or intensifying an antihypertensive treatment for a patient who is not at the blood pressure goals defined for this patient in the guidelines when all the following conditions are met.

1. Hypertension has been confirmed by self-measurement or ambulatory BP monitoring

2. There is no doubt on the reliability of the measurement

3. The difference between the measurement and recommended target is significant

4. There is no observance issue (including lifestyle and diet)

5. There is no specific iatrogenic risk (which modifies the risk-benefit balance of treatment for this patient)

6. There is no other medical priority

7. There is no difficulty in accessing the treatment

Appropriate inaction means not initiating or intensifying an antihypertensive treatment for a patient who is not at the blood pressure goals defined for this patient in the guidelines when at least one of the following condition is met.

1. Hypertension has not been confirmed by self-measurement or ambulatory BP monitoring

2. There is a doubt on the reliability of the measurement

3. The difference between the measurement and recommended target is not significant

4. There is an observance issue (including lifestyle and diet)

5. There is a specific iatrogenic risk (which modifies the risk-benefit balance of treatment for this patient)

6. There is another medical priority

7. There is a difficulty in accessing the treatment

inaction', and that other priorities should be clearly 'more important and more urgent'.

The new definitions of inappropriate inertia and appropriate inaction in the management of patients with hypertension in primary care resulting from the first round are detailed in box 3 .
Box 3 Final definitions of inappropriate inertia and appropriate inaction in the management of patients with hypertension in primary care

Definition of inappropriate inertia in the management of patients with hypertension in primary care:

To not initiate or intensify an antihypertensive treatment for a patient who is not at the blood pressure goals defined for this patient in the guidelines when all these conditions are fulfilled:

1. Elevated blood pressure has been confirmed by self-measurement* or ambulatory BP monitoring

2. There is no legitimate doubt on the reliability of the measurements

3. There is no observance issue regarding pharmacological treatment

4. There is no specific iatrogenic risk (which alters the risk-benefit balance of treatment for this patient), in particular orthostatic hypotension in the elderly

5. There is no other medical priority more important and more urgent

6. Access to the treatment is not difficult

Definition of appropriate inaction in the management of patients with hypertension in primary care:

To not initiate or intensify antihypertensive treatment for a patient who is not at the blood pressure goals defined for this patient in the guidelines when at least one of these conditions happens:

1. Elevated blood pressure has not been confirmed by self-measurement $^{\star}$ or ambulatory BP monitoring

2. There is a legitimate doubt on the reliability of the measurements

3. There is an observance issue regarding pharmacological treatment

4. There is a specific iatrogenic risk (which alters the risk-benefit balance of treatment for this patient), in particular orthostatic hypotension in the elderly

5. There is another medical priority more urgent and more important

6. Access to the treatment is difficult (ie, financial issues)

: "self-measurement" also refers to home blood pressure monitoring (HBPM).

\section{Second round}

The same 19 experts answered the second questionnaire. Their answers are detailed in table 4. Strong agreement and consensus were reached for both definitions. Experts also strongly agreed with the changes made in the definitions after the first round. No further

Table 3 Results of the Delphi procedure round 1

\begin{tabular}{|c|c|c|c|c|c|c|c|c|}
\hline Questions & Items & $\begin{array}{l}\text { Median } \\
\text { score }\end{array}$ & $\begin{array}{l}\text { Scores } \\
\text { ranking from } \\
1 \text { to } 3(\%)\end{array}$ & $\begin{array}{l}\text { Scores } \\
\text { ranking from } \\
4 \text { to } 6(\%)\end{array}$ & $\begin{array}{l}\text { Scores } \\
\text { ranking from } \\
7 \text { to } 9(\%)\end{array}$ & $\begin{array}{l}\text { Agreement } \\
\text { between } \\
\text { experts }\end{array}$ & Consensus & $\begin{array}{l}\text { Decision on } \\
\text { the proposal }\end{array}$ \\
\hline Q 1 & & 5 & 42 & 16 & 42 & No & No & None \\
\hline \multirow[t]{3}{*}{ Q 2} & 1 & 4 & 47 & 16 & 37 & No & No & None \\
\hline & 2 & 4 & 47 & 26 & 26 & Yes & No & None \\
\hline & 3 & 3 & 63 & 21 & 16 & Yes & Yes & Rejected \\
\hline Q 3 & & 7 & 16 & & 68 & Yes & Yes & Accepted \\
\hline Q 4 & & 7 & 11 & 21 & 68 & Yes & Yes & Accepted \\
\hline \multirow[t]{3}{*}{ Q 5} & 1 & 8 & 5 & 5 & 89 & Yes & Yes & Accepted \\
\hline & 2 & 7 & 11 & 21 & 68 & Yes & Yes & Accepted \\
\hline & 3 & 7 & 11 & 16 & 74 & Yes & Yes & Accepted \\
\hline
\end{tabular}

Bold values: propositions that reached agreement and consensus to be either accepted or rejected. 
Table 4 Results of the Delphi procedure round 2

\begin{tabular}{lllllllll}
\hline Questions & Items & $\begin{array}{l}\text { Median } \\
\text { score }\end{array}$ & $\begin{array}{l}\text { Scores } \\
\text { ranking from } \\
\mathbf{1} \text { to } \mathbf{3} \text { (\%) }\end{array}$ & $\begin{array}{l}\text { Scores } \\
\text { ranking from } \\
\mathbf{4} \text { to } \mathbf{6} \text { (\%) }\end{array}$ & $\begin{array}{l}\text { Scores } \\
\text { ranking from } \\
\mathbf{7} \text { to } \mathbf{9} \text { (\%) }\end{array}$ & $\begin{array}{l}\text { Agreement } \\
\text { between } \\
\text { experts }\end{array}$ & Consensus & $\begin{array}{l}\text { Decision on } \\
\text { the proposal }\end{array}$ \\
\hline Q1 & & 4 & 42 & 26 & 37 & No & No & None \\
Q 2 & 1 & 3 & 58 & 16 & 26 & Yes & Yes & Rejected \\
& 2 & 3 & 58 & 16 & 26 & Yes & Yes & Rejected \\
& 3 & 3 & 68 & 26 & 5 & Yes & Yes & Rejected \\
Q 3 & & 7 & 5 & 26 & 68 & Yes & Yes & Accepted \\
Q 4 & & 8 & 5 & 16 & 79 & Yes & Yes & Accepted \\
Q 5 & 1 & 8 & 5 & 0 & 95 & Yes & Yes & Accepted \\
& 2 & 7 & 5 & 16 & 79 & Yes & Yes & Accepted \\
& 3 & 7 & 5 & 16 & 79 & Yes & Yes & Accepted \\
\hline
\end{tabular}

modifications were made, and the definitions resulting from the first round became the final results (box 3).

\section{DISCUSSION}

\section{Main result}

This study enabled the development and validation of operational definitions for appropriate inaction (AI) and inappropriate inertia in the management of patients with hypertension. The use of an international expert consensus based on empirical data gathered from primary care practitioners give these results clinical and academic legitimacy. This allows consideration of their use for both clinical practice and clinical research.

Our international panel of academic experts strongly agreed that the original definition of TI was not operational for practice or research. The main reasons were that it did not take into account clinical uncertainty, prioritisation of problems and the complexity of the relationship between the GP and the patient. For the new definition presented here, although a second round was used to refine the new definitions in regard to the experts' comments, the consensus was already strong after the first round. Because they were developed for an international use, these definitions include 'access to treatment' issues, which highly depends on local health policies.

These definitions take into account two of the three aspects of evidence-based medicine: the available scientific data and the caregiving situation. They do not take account of patient opinions and values. They do not include, as proposed by one of the experts, the quality of the doctor-patient relationship, because these aspects are part of any caregiving situation and not specific to those where inaction occurs in the management of a patient with hypertension. Further, the inner subjectivity and the major complexity of shared decision-making would have made the definitions too complicated and would have left the possibility to regard inaction as appropriate in almost any situation. Nevertheless, the final decision, shared and patient-centred, should of course always take in account the patient's opinions and values.
In the case of appropriate inaction, some items in the definition call for specific action, in particular to obtain reliable blood pressure measurements or enhance observance. Failure to do this would result in poor quality of care, but these are different problems that would require specific research and interventions.

\section{Strengths and limitations}

Complex conceptual issues and contradictory data from the existing literature called for a consensus method. ${ }^{19}$ The need for empirical data regarding behaviours in real life led to the choice of the nominal group technique. Focus groups were a possible choice but would have made the ranking of reasons for inaction impossible, and thereby would have meant even more subjective input from the research team in the results. ${ }^{17}$ Careful purposive sampling of the participants ensured a wide sample of answers. Results from the two groups were very similar, which makes them even more robust.

As a limitation, the nominal groups were held in France and included French GPs only. However, nominal groups were only conducted as a first step to provide the elements of definitions, to be validated by the panel of academic experts, which was international. Making sure that the definitions would be suitable in any country, by adding, removing or modifying items if necessary was the task of this panel.

To clarify the results of the nominal groups and make them useable for the design of definitions, proposals were grouped into categories by the research team. The interpretation bias was minimised by having two teams doing this independently and including final arbitration by a third team. Feedback from the participants showed unanimous agreement with the results.

Questions 3 and 4 of the Delphi procedure were asking for the agreement of the experts with the proposed definitions. The phrasing did not specifically include 'operationality' as did questions 1 and 2. We considered that rejecting the operationality of the former definition while agreeing with the new ones meant that the last were regarded as operational, which was a questionable shortcut. 
The characteristics and the number of participants in a Delphi study are always questionable. ${ }^{1516}$ We selected a panel that was international, with academics that worked and published in the specific field of TI in hypertension. A major concern was to get the highest possible proportion of experts completing the procedure and to have at least 15 of them at the end. ${ }^{16}$ All 19 experts involved completed the procedure.

\section{Findings compared with the existing literature}

In his 2001 princeps article, Philipps gave very little room to either appropriate inaction or patient centerednessjust a note of caution that 'experienced clinicians will recognise that exceptions always occur and that rigid insistence on the uniform application of guidelines for patient management could result in overtreatment or inappropriate actions. ${ }^{8}$ Nevertheless, subsequent calls to action were based on a 'run the numbers and treat to targets' attitude that seemed to oversimplify the process of care. ${ }^{11}$

In response, some authors pointed out that inaction could also be a 'clinical safeguard' vis-à-vis the drug escalation fuelled by the current medical literature and could represent good clinical judgment. ${ }^{13} 20$ This new approach to inaction relied on evidence that showed that physician tolerance of borderline blood pressure values frequently resulted in good blood pressure control during follow-up. ${ }^{21}$

In 2007, starting from the premise that appropriate and inappropriate inaction coexisted in TI, Safford et al proposed an empirical model based on nominal groups of primary care physicians. ${ }^{22}$ This model individualised four types of clinical inertia: appropriate inaction related either to the physician or to the patient, and TI related either to the physician or to the patient. While these four types were clearly delimited in a cognitive map, no definitions were proposed. Although these results were important to understand the various mechanisms involved in inaction, they did not allow an immediate use in clinical practice.

\section{Perspectives for practice and research}

The definitions proposed here may be used as a basis in the negotiation between the practitioner and the patient with hypertension. Each of them could be used in a checklist for the physician, providing an evidence-based foundation for shared decision-making. In the educational field, they could be used to easily outline TI to medical students and trainees in general practice. Furthermore, a good vocabulary can indeed help to clarify in learning practice the choices that trainees make when discussing options with their patients.

Until now, interventions relating to TI have been based only on the physician's action resulting from blood pressure measurements, with no consideration for the context or for sociopsychological issues. Further research could use our results to explore the reasons for or consequences of inaction, and to characterise inaction in pragmatic studies. Ultimately, they could help design interventions to reduce inappropriate inertia while preserving appropriate inaction.

Acknowledgements The authors thank all the primary care physicians who participated in the nominal groups and the academic experts who participated in the Delphi procedure for their cooperation and strong commitment to the project. The authors also thank Carolyn Daher for reviewing the manuscript. Experts who participated in the Delphi procedure were (in alphabetical order): Professor Claude Attali (Univerisity of Paris-Est-Creteil, France), Professor Jan Basile (University of South Carolina, USA), Professor Jean-Marc Boivin (University of Nancy, France), Dr Thierry Brillac (University of Toulouse, France), Dr Concepcion Carratala-Munuera (University of Alicante, Spain), Assistant Professor Matthew Crowley (Duke Clinical Research Institute, USA), Professor Didier Giet (University of Liege, Belgium), Professor Vicente Gil-Guillen (University of Alicante, Spain), Professor Jean-Michel Halimi (University of Tours, France), Professor Clovis Hoepfner (University of Joinville, Brasil), Dr Faline Howes (University of Tasmania, Australia), Dr Amanda Kennedy (University of Vermont, USA), Professor Lawrence Krakoff (Mount Sinai School of Medicine, USA), Professor Jean-Jacques Mourad (University of Paris 13-Bobigny, France), Dr Patrick O'Connor (HealthPartners Institute, Minneapolis, USA), Professor Lawrence Phillips (Emory University, Atlanta, USA), Professor Gerard Reach (University of Paris 13-Bobigny, France), Dr Monika Safford (University of Alabama at Birmingham and Cornell Medical College, New-York, USA) and Dr Frederic Villeneuve (Cardiovascular Prevention Institute, Paris, France).

Contributors J-PL, JB (for the Delphi procedure), MC (for the nominal groups), AM and IA-A: designed the study and carried out the data collection and analysis. ER, $\mathrm{RR}, \mathrm{EV}$ and $\mathrm{KH}$ : audited the whole methodological process. All authors contributed to the interpretation of findings and to creation of initial, modified and final definitions; contributed to the development of the manuscript; had full access to all of the data in the study, and can take responsibility for the integrity and accuracy of the analysis.

Funding This research received no specific grant from any funding agency in the public, commercial or not-for-profit sectors.

Disclaimer The first author declares that the article is an honest, accurate and transparent account of the study.

Competing interests None declared.

Provenance and peer review Not commissioned; externally peer reviewed.

Data sharing statement Extra data can be accessed via the Dryad data repository at http://datadryad.org/ with the doi: 10.5061/dryad.v48k5p9.

Open access This is an open access article distributed in accordance with the Creative Commons Attribution Non Commercial (CC BY-NC 4.0) license, which permits others to distribute, remix, adapt, build upon this work non-commercially, and license their derivative works on different terms, provided the original work is properly cited, appropriate credit is given, any changes made indicated, and the use is non-commercial. See: http://creativecommons.org/licenses/by-nc/4.0/.

\section{REFERENCES}

1. World health organization. A global brief on hypertension. Silent killer, global public health crisis. Geneva: WHO, 2013.

2. Yoon SS, Gu Q, Nwankwo T, et al. Trends in blood pressure among adults with hypertension: United States, 2003 to 2012. Hypertension 2015;65:54-61.

3. Sipilä R, Helin-Salmivaara A, Korhonen MJ, et al. Change in antihypertensive drug prescribing after guideline implementation: a controlled before and after study. BMC Fam Pract 2011;12:87.

4. Jeffery RA, To MJ, Hayduk-Costa G, et al. Interventions to improve adherence to cardiovascular disease guidelines: a systematic review. BMC Fam Pract 2015;16:147.

5. Herttua K, Tabák AG, Martikainen P, et al. Adherence to antihypertensive therapy prior to the first presentation of stroke in hypertensive adults: population-based study. Eur Heart $J$ 2013;34:2933-9.

6. Appel LJ, Champagne CM, Harsha DW, et al. Effects of comprehensive lifestyle modification on blood pressure control: main results of the PREMIER clinical trial. JAMA 2003;289:2083-93.

7. Marshall IJ, Wang Y, Crichton S, et al. The effects of socioeconomic status on stroke risk and outcomes. Lancet Neurol 2015;14:1206-18.

8. Phillips LS, Branch WT, Cook CB, et al. Clinical inertia. Ann Intern Med 2001;135:825-34. 
9. Okonofua EC, Simpson KN, Jesri A, et al. Therapeutic inertia is an impediment to achieving the Healthy People 2010 blood pressure control goals. Hypertension 2006;47:345-51.

10. Wang YR, Alexander GC, Stafford RS. Outpatient hypertension treatment, treatment intensification, and control in Western Europe and the United States. Arch Intern Med 2007;167:141-7.

11. Phillips LS, Twombly JG. It's time to overcome clinical inertia. Ann Intern Med 2008;148:783-5.

12. Bosworth HB, Olsen MK, Dudley T, et al. Patient education and provider decision support to control blood pressure in primary care: a cluster randomized trial. Am Heart J 2009;157:450-6.

13. Giugliano D, Esposito K. Clinical inertia as a clinical safeguard. JAMA 2011;305:1591-2.

14. Lebeau JP, Cadwallader JS, Aubin-Auger I, et al. The concept and definition of therapeutic inertia in hypertension in primary care: a qualitative systematic review. BMC Fam Pract 2014;15:130.

15. Jones J, Hunter D. Consensus methods for medical and health services research. BMJ 1995;311:376-80.
16. Fink A, Kosecoff J, Chassin M, et al. Consensus methods: characteristics and guidelines for use. Am J Public Health 1984;74:979-83.

17. Gallagher M, Hares T, Spencer J, et al. The nominal group technique: a research tool for general practice? Fam Pract 1993;10:76-81.

18. Hasson F, Keeney S, McKenna H. Research guidelines for the Delphi survey technique: Delphi survey technique. Journal of Advanced Nursing 2000;32:1008-15.

19. Buccini LD, Caputi $P$, Iverson $D$, et al. Toward a construct definition of informed consent comprehension. J Empir Res Hum Res Ethics 2009;4:17-23.

20. Krakoff LR, Kronish IM. Guidelines, inertia, and judgment. Hypertension 2011;58:544-5.

21. Crowley MJ, Smith VA, Olsen MK, et al. Treatment intensification in a hypertension telemanagement trial: clinical inertia or good clinica judgment? Hypertension 2011;58:552-8.

22. Safford MM, Shewchuk R, Qu H, et al. Reasons for not intensifying medications: differentiating "clinical inertia" from appropriate care. $J$ Gen Intern Med 2007;22:1648-55. 